\section{Investigation of EscA as a chaperone for the Edwardsiella tarda type III secretion system putative translocon component EseC

\author{
Bo Wang, ${ }^{1,2}$ Zhao Lan Mo, ${ }^{1}$ Yun Xiang Mao, ${ }^{3}$ Yu Xia Zou, ${ }^{1}$ Peng Xiao, ${ }^{1,2}$ \\ Jie Li, ${ }^{3}$ Jia Yin Yang, ${ }^{1,2}$ Xu Hong Ye, ${ }^{3}$ Ka Yin Leung ${ }^{4}$ and Pei Jun Zhang ${ }^{1}$ \\ ${ }^{1}$ Institute of Oceanology, Chinese Academy of Sciences, Qingdao 266071, PR China \\ ${ }^{2}$ Graduate University of Chinese Academy of Sciences, Beijing 100049, PR China \\ ${ }^{3}$ Ocean University of China, Qingdao 266003, PR China \\ ${ }^{4}$ Department of Biological Sciences, Faculty of Science, National University of Singapore, 117543
} Singapore}

\begin{abstract}
Edwardsiella tarda is an important Gram-negative enteric pathogen affecting both animals and humans. It possesses a type III secretion system (T3SS) essential for pathogenesis. EseB, EseC and EseD have been shown to form a translocon complex after secretion, while EscC functions as a T3SS chaperone for EseB and EseD. In this paper we identify EscA, a protein required for accumulation and proper secretion of another translocon component, EseC. The escA gene is located upstream of eseC and the EscA protein has the characteristics of T3SS chaperones. Cell fractionation experiments indicated that EscA is located in the cytoplasm and on the cytoplasmic membrane. Mutation with in-frame deletion of escA greatly decreased the secretion of EseC, while complementation of esc $A$ restored the wild-type secretion phenotype. The stabilization and accumulation of EseC in the cytoplasm were also affected in the absence of EscA. Mutation of esc $A$ did not affect the transcription of eseC but reduced the accumulation level of EseC as measured by using an EseC-LacZ fusion protein in Ed. tarda. Co-purification and coimmunoprecipitation studies demonstrated a specific interaction between EscA and EseC. Further analysis showed that residues 31-137 of EseC are required for EseC-EscA interaction. Mutation of EseC residues 31-137 reduced the secretion and accumulation of EseC in Ed. tarda. Finally, infection experiments showed that mutations of EscA and residues 31-137 of EseC increased the $\mathrm{LD}_{50}$ by approximately 10 -fold in blue gourami fish. These results indicated that EscA functions as a specific chaperone for EseC and contributes to the virulence of Ed. tarda.
\end{abstract}

Received 14 July 2008

Revised 7 December 2008

Accepted 17 December 2008

\section{INTRODUCTION}

Edwardsiella tarda is a facultative aerobic Gram-negative pathogen with a wide host range, infecting animals including fish (Sae-Oui et al., 1984), amphibians (Kourany et al., 1977), reptiles (Goldstein et al., 1981), birds (Cook \& Tappe, 1985) and mammals (including humans) (Janda \& Abbott, 1993). Edwardsiellosis, caused by Ed. tarda, has been found in many commercially important cultured fish, and leads to extensive losses in both freshwater and marine aquaculture (Thune et al., 1993). In humans, Ed. tarda can cause gastrointestinal (Janda \& Abbott, 1993) and extraintestinal infections (Yang \& Wang, 1999). The pathogenesis of Ed. tarda is multifactorial, including factors that

Abbreviations: ECP, extracellular protein; EPEC, enteropathogenic E. coli; ICP, intracellular protein; T3SS, type III secretion system (F-T3SS and NF-T3SS, flagellar and non-flagellar T3SS). enable the bacteria to invade non-phagocytic cells (Kourany et al., 1977; Ling et al., 2000), survive in phagocytes (Srinivasa Rao et al., 2001, 2003), and produce virulence factors such as haemolysins (Janda \& Abbott, 1993; Chen et al., 1996) and catalases (Srinivasa Rao et al., 2003). Recently, two important protein secretion systems, a type III secretion system (T3SS) (Tan et al., 2005; Zheng et al., 2007) and a type VI secretion system (T6SS) (Zheng \& Leung, 2007), have been demonstrated to be virulence-associated.

Flagellar and non-flagellar systems (Saier, 2004; Pallen et al., 2005) constitute two broad classes of T3SSs. Flagellar type III secretion systems (F-T3SSs) are responsible for the export of flagellum components (Macnab, 2003), while non-flagellar type III secretion systems (NF-T3SSs) translocate proteins across both the bacterial envelope and the eukaryotic plasma membrane in an ATPase-dependent fashion (Pallen et al., 2005). Two kinds of proteins secreted 
include the anti-host effectors, which are translocated into the cytosol of the target cells, where they subvert a variety of cellular processes (Waterman \& Holden, 2003; Ghosh, 2004), and the translocon proteins, which form pores in a host cell's plasma membrane through which the effectors can enter the infected cell (Büttner \& Bonas, 2002).

Efficient secretion of proteins through any T3SS usually depends upon the presence of chaperones that bind to the T3SS-secreted proteins (Parsot et al., 2003). Chaperones stabilize newly synthesized proteins, protecting them from aggregation and proteolysis in the cytoplasm, and then deliver proteins to the secretion apparatus (Parsot et al., 2003; Ghosh, 2004). In addition, some T3SS chaperones also function as regulators for T3SS gene expression and/or protein secretion (Darwin \& Miller, 2001; Francis et al., 2002). Two distinct functional classes of chaperones exist for NF-T3SSs: class I chaperones, which bind to effectors, and class II chaperones, which bind to translocons (Page \& Parsot, 2002; Parsot et al., 2003). Class I chaperones share a moderate degree of sequence homology, with a common mixed $\alpha / \beta$-helical fold (Parsot et al., 2003; Pallen et al., 2005), while some class II chaperones have been recently reported to share TPR-like motifs (Bröms et al., 2006; Edqvist et al., 2006; Büttner et al., 2008). Interactions of class II chaperones and their substrates are necessary for functions involving regulatory, structural and effector mechanisms (Delahay \& Frankel, 2002; Olsson et al., 2004), while some class II chaperones are reported to have defined regions that interact with their cognate substrates (Daniell et al., 2003; Edqvist et al., 2006).

In pathogenic Ed. tarda, an identified T3SS contains 35 open reading frames. EseB, $\mathrm{EseC}$ and $\mathrm{EseD}$ have been shown to be major components of the extracellular proteins secreted by the T3SS (Tan et al., 2005), and these three proteins form a protein complex after secretion (Zheng et al., 2007). EseB, EseC and EseD are respectively homologous to translocon components EspA, EspD and EspB of enteropathogenic Escherichia coli (EPEC) (Ide et al., 2001), and to the translocon components SseB, SseC and SseD of Salmonella spp. (Nikolaus et al., 2001). These findings suggest that EseB, EseC and EseD may function as translocon components, facilitating the translocation of effectors. These three Ese proteins contribute to $E d$. tarda pathogenesis, as mutation of $e s e B, e s e C$ or eseD led to a 10 -fold decrease in virulence compared to the wild-type (Tan et al., 2005).

As chaperones are key mediators of the T3SS virulence strategy, previous research was designed to identify the chaperones of $E d$. tarda T3SS. One chaperone, EscC, was shown to function as a T3SS chaperone for the putative translocon components EseB and EseD (Zheng et al., 2007). However, no chaperone has hitherto been identified for another putative translocon component, EseC. EseC is homologous to proteins belonging to the EspD family (YopB from Yersinia and IpaB from Shigella), which require chaperones in order to properly perform their functions (Cornelis \& Van Gijsegem, 2000; Büttner \&
Bonas, 2002). Analysis of the secondary structure indicated that the EseC protein contains two predicted hydrophobic transmembrane domains and two coiled-coil domains (Fig. 1B), similar to its homologues, such as EspD and YopB. These observations suggested that EseC may have functions similar to those of homologues involved in the pathogenesis process of cell attachment, pore formation and translation of effectors (Cornelis \& Van Gijsegem, 2000; Büttner \& Bonas, 2002). The escA gene is located upstream of eseC (Fig. 1A) and the EscA protein is homologous to the class II chaperones in other bacterial species such as CesD (38\% identity and $57 \%$ similarity) in EPEC (Wainwright \& Kaper, 1998), LcrH/SycD (24\% identity and $48 \%$ similarity) in Yersinia spp. (Neyt \& Cornelis, 1999), PcrH (23\% identity and $42 \%$ similarity) in Pseudomonas spp. (Bröms et al., 2003) and IpgC (23\% identity and $42 \%$ similarity) in Shigella spp. (Ménard et al., 1994). Interestingly, CesD was shown to interact with EspD but not EspB; this interaction is required in order to ensure proper secretion of EspD and EspB. However, IpgC was shown to bind directly to two translocon proteins (IpaB and IpaC) in the cytoplasm (Ménard et al., 1994). Given the similarity of EseC and EspD, EscA could play a role similar to that of CesD and may be required for proper secretion of EseC. Here we present evidence that EscA functions as a specific chaperone responsible for the stabilization and efficient secretion of EseC in Ed. tarda. In addition, a defined domain in $\mathrm{EseC}$ is demonstrated to be required for the interaction between EseC and EscA to occur. This domain also plays a role in the pathogenesis of Ed. tarda.

\section{METHODS}

Bacteria strains, plasmids, culture media and growth conditions. The bacterial strains and plasmids used in this study are listed in Table 1. E. coli strains were routinely grown at $37{ }^{\circ} \mathrm{C}$ on LB-agar plates or with shaking in LB-broth (Difco). Ed. tarda strains were grown at $25{ }^{\circ} \mathrm{C}$ on tryptic soy agar (TSA) plates or with shaking in tryptic soy broth (TSB, Difco). For the induction of T3SS expression, Ed. tarda strains were grown without shaking in a $5 \%(\mathrm{v} / \mathrm{v}) \mathrm{CO}_{2}$ incubator at $25^{\circ} \mathrm{C}$ in Dulbecco's modified Eagle medium (DMEM, Invitrogen). When required, culture media were supplemented with appropriate antibiotics: ampicillin (Amp, $50 \mu \mathrm{g} \mathrm{ml}^{-1}$ ), colistin (Col, $\left.12.5 \mu \mathrm{g} \mathrm{ml}^{-1}\right)$, kanamycin $\left(\mathrm{Km}, 50 \mu \mathrm{g} \mathrm{ml}^{-1}\right)$, chloramphenicol $(\mathrm{Cm}$, $34 \mu \mathrm{g} \mathrm{ml}^{-1}$ ) and tetracycline (Tet, $50 \mu \mathrm{g} \mathrm{ml}^{-1}$ ).

Construction of in-frame deletion mutants of Ed. tarda PPD130/91. Overlap PCR was used to generate in-frame deletion fragments. The unmarked in-frame deletion mutants in Ed. tarda PPD130/91 were constructed according to a previously described method (Mo et al., 2007). The $\Delta e s c A$ mutant removed codons 2-130 of EscA, whereas the $\Delta e s e C_{31-137}$ mutant removed an internal fragment of codons 31-137 of EseC.

To create a complementing plasmid for the $\triangle e s c A$ mutant, the escA gene was amplified and introduced into plasmid pACYC184. The resulting plasmid, pACYC184-escA, was transformed into the $\triangle e s c A$ mutant to produce $\triangle e s c A+e s c A$.

Construction of the recombinant EscA protein and generation of polyclonal antibody. The polyclonal anti-EscA antibody was 
A

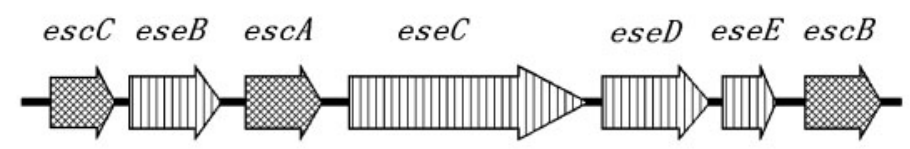

B

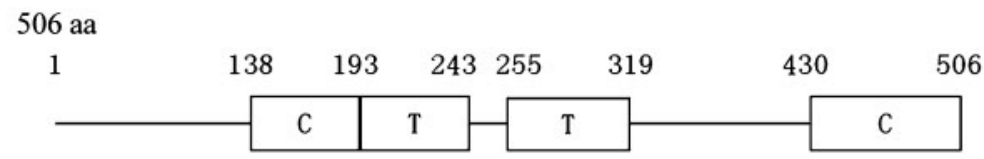

C

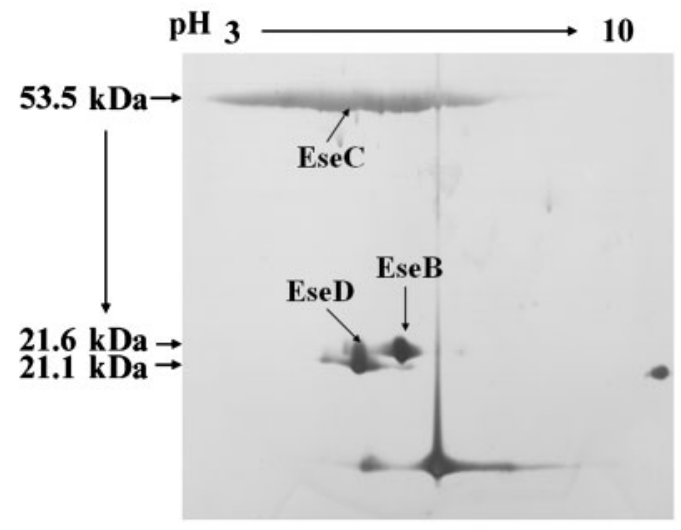

wild-type
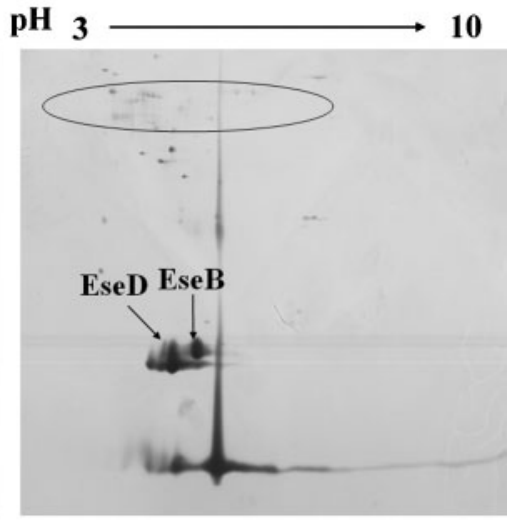

escA mutant

D

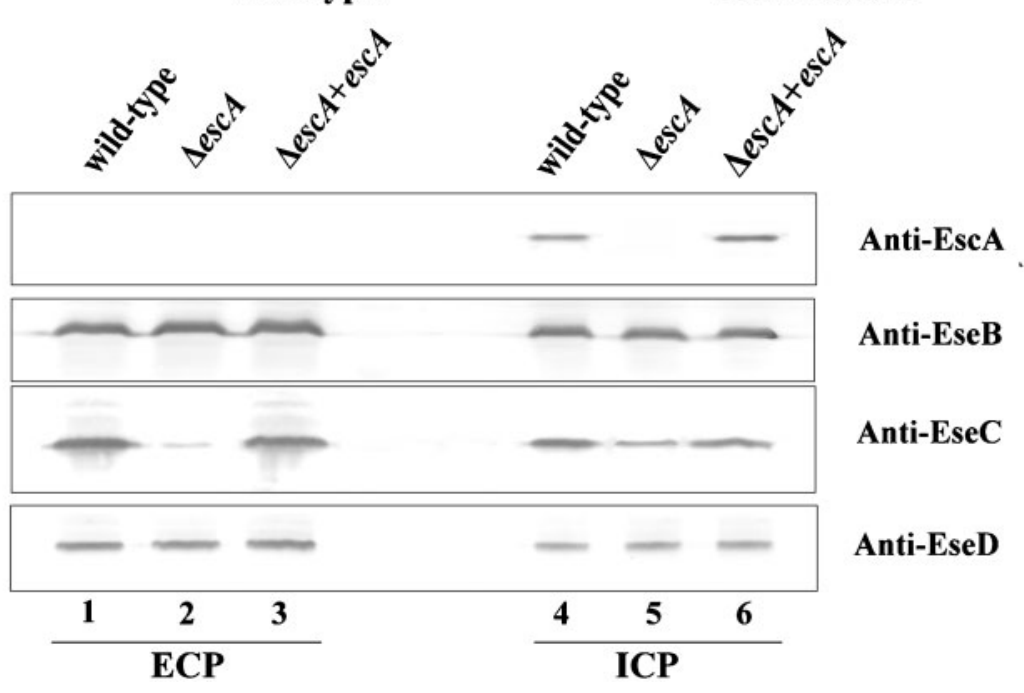

Fig. 1. Effect of EscA on the secretion and accumulation of EseC. (A) Schematic representation of the escA-eseC region of Ed. tarda. (B) Schematic representation of the secondary structure of the EseC protein, indicating the predicted transmembrane (T) and coiled-coil (C) regions. (C) 2D PAGE analysis of the supernatant proteins of the Ed.tarda wild-type strain and $\Delta$ esc $A$ mutant cultured in DMEM at $25{ }^{\circ} \mathrm{C}$ with $5 \%(\mathrm{v} / \mathrm{v}) \mathrm{CO}_{2}$ for $24 \mathrm{~h}$. Supernatant proteins of each strain were separated on Immobiline DryStrips (pH 3-10) and adjusted according to the relative amount of proteins secreted by each strain: wild-type $(10 \mu \mathrm{g})$ and $\operatorname{sesc} A(5 \mu \mathrm{g})$. Gels $(12.5 \%$ polyacrylamide) were silver-stained. Translocon proteins EseB, EseC and EseD are indicated. (D) Western blotting analysis of the extracellular proteins (ECPs) and intracellular proteins (ICPs) of Ed. tarda wildtype, $\Delta e s c A$ and $\Delta e s c A+e s c A$ strains. Bacteria were adjusted to an equivalent amount of cells $\left(\mathrm{OD}_{540} 0.5\right)$. The ECPs and ICPs of each strain were extracted from equal amounts of cells and analysed by Western blotting using anti-EscA, -EseB, -EseC and -EseD polyclonal antibodies. Relative units of the EseC proteins in (D), as measured with the Fluor-S Multi-imager (Bio-Rad), were as follows: wild-type ECP (lane 1), 100.0; $\Delta$ esc $A$ mutant ECP (lane 2), $1.5 \pm 0.5 ; \Delta \operatorname{esc} A+\operatorname{esc} A$ ECP (lane 3), 95.2 \pm 3.0 ; wild-type ICP (lane 4), 36.6 $\pm 3.4 ; \Delta e s c A$ mutant ICP (lane 5), $9.7 \pm 1.2$; and $\Delta \operatorname{esc} A+\operatorname{esc} A$ ICP (lane 6), $35.4 \pm 4.2$. 
Table 1. Strains and plasmids used in this study

\begin{tabular}{|c|c|c|}
\hline Strain or plasmid & Description or genotype & Reference or source \\
\hline \multicolumn{3}{|l|}{ E. coli } \\
\hline DH5 $\alpha$ & supE44 $\Delta$ lacU169 ( $\phi 80$ lacZAM15) hsdR17 recA1 gyrA96 thi-1 relA1 & Hanahan (1983) \\
\hline SM10 ( $\lambda$ pir) & thi thr leu tonA lacY supE recA-RP4-2-Tc-Mu $\mathrm{Km}^{\mathrm{r}} \lambda$ pir & Miller \& Mekalanos (1988) \\
\hline BL21(DE3)/pLysS & $\mathrm{F}^{-}$ompT hsdS $\left(\mathrm{r}_{\mathrm{B}}^{-} \mathrm{m}_{\mathrm{B}}^{-}\right)$gal dcm (DE3) tonA $\mathrm{pLysS}\left(\mathrm{Cm}^{\mathrm{r}}\right)$ & Tan et al. (2005) \\
\hline SY327 (ipir) & $\Delta($ lac, pro $) \arg E(\mathrm{Am})$ rif malA recA56 $\lambda$ pir & Miller \& Mekalanos (1988) \\
\hline \multicolumn{3}{|c|}{1} \\
\hline PPD130/91 & Wild-type, $\mathrm{Col}^{\mathrm{r}} \mathrm{Km}^{\mathrm{s}} \mathrm{Amp}^{\mathrm{s}}$ & Ling et al. (2000) \\
\hline$\Delta e s c A$ & PPD130/91, escA in-frame deletion of codons $2-130$ & This study \\
\hline$\Delta e s e C_{31-137}$ & PPD130/91, eseC in-frame deletion of codons 31-137 & This study \\
\hline$\Delta e s c A+e s c A$ & PPD130/91, $\Delta e s c A$ carrying pACYC184-escA & This study \\
\hline eseC::pVIK111 & PPD130/91, in-frame eseC-lacZ translational fusion & This study \\
\hline \multicolumn{3}{|l|}{ Plasmids } \\
\hline pGEMT-easy & Cloning vector; $\mathrm{Amp}^{\mathrm{r}}$ & Promega \\
\hline pRE112 & pGP704 suicide plasmid, pir dependent, $\mathrm{Cm}^{\mathrm{r}}$ oriT oriV $s a c B$ & Edwards et al. (1998) \\
\hline pETDuet-1 & Expression vector, $A m p^{r}$ & Novagen \\
\hline pACYC184 & Cloning vector, $\mathrm{Cm}^{\mathrm{r}} \mathrm{Tc}^{\mathrm{r}}$ & Fermentas Life Sciences \\
\hline pA1 & pETDuet-1 with escA in MCS1 (encodes $\mathrm{His}_{6}$-EscA) & This study \\
\hline $\mathrm{pC} 1$ & pETDuet-1 with eseC in MCS1 (encodes $\mathrm{His}_{6}$-EseC) & This study \\
\hline pC2 & pETDuet-1 with eseC in MCS2 (encodes EseC) & This study \\
\hline $\mathrm{pAC}$ & pETDuet-1 with escA in MCS1 and eseC in MCS2 (encodes His $_{6}$-EscA + EseC) & This study \\
\hline $\mathrm{pAC}_{\Delta 1-30}$ & ese $C_{\Delta 1-30}$ fragment introduced into MCS2 of pA1 & This study \\
\hline $\mathrm{pAC}_{\Delta 31-137}$ & ese $C_{\Delta 31-137}$ fragment introduced into MCS2 of pA1 & This study \\
\hline
\end{tabular}

generated according to a previously established method (Zheng et al., 2007). For generation of the EscA recombinant protein, the escA gene was amplified by PCR and cloned into the MCS1 (multiple cloning site 1) of pETDuet-1, yielding plasmid pA1 with an N-terminal $\mathrm{His}_{6}{ }^{-}$ tag. The recombinant EscA was expressed in E. coli BL21(DE3)/pLysS and purified with $\mathrm{Ni}^{2+}$-NTA agarose beads under conditions recommended by the manufacturer (Qiagen). The purified $\mathrm{His}_{6}$ EscA protein was used to immunize New Zealand White rabbits.

\section{Construction of recombinant plasmids encoding $\mathrm{His}_{6}$-EscA+} EseC and $\mathbf{H i s}_{\mathbf{6}}$-EscA+EseC $\mathbf{\Delta}$. For construction of the recombinant plasmid encoding $\mathrm{His}_{6}$-EscA and EseC, the ese $\mathrm{C}$ gene was amplified and introduced into MCS2 (multiple cloning site 2) of pA1, yielding the plasmid pAC. For comparison, the eseC gene was then introduced into MCS1 and MCS2 of pETDuet-1 to produce plasmids $\mathrm{pC} 1$ and $\mathrm{pC} 2$, respectively.

The in-frame deletion fragments of ese $C$ were constructed following the overlap extension PCR procedure described above. The resulting fragments were introduced into MCS2 of pA1, giving plasmids $\mathrm{pAC}_{\Delta 1-30}, \quad \mathrm{pAC}_{\Delta 31-137}, \mathrm{pAC}_{\Delta 138-193}, \mathrm{pAC}_{\Delta 194-243}, \quad \mathrm{pAC}_{\Delta 255-318}$, $\mathrm{pAC}_{\Delta 319-402}, \mathrm{pAC}_{\Delta 403-429}$ and $\mathrm{pAC}_{\Delta 430-506}$ (Table 1). These plasmids encode various $\mathrm{His}_{6}$-EscA $+\mathrm{EseC} \Delta$ proteins. The recombinant plasmids were transformed into E. coli BL21(DE3)/pLysS.

Preparation of proteins of cell fractions. To prepare each protein fraction, $E d$. tarda was cultured in DMEM to induce expression of the T3SS, and the equivalent of $\mathrm{OD}_{540}=0.5$ bacterial cultures were analysed. The supernatant proteins, cell surface proteins and intracellular proteins were collected according to the method described by Beuzón et al. (1999) with some modification. Briefly, the bacterial cells were separated from $5 \mathrm{ml}$ culture by centrifugation at $5000 \mathrm{~g}$ for 5 min at $4{ }^{\circ} \mathrm{C}$; the culture supernatant was filtered through a $0.22 \mu \mathrm{m}$ Millipore membrane filter and subsequently precipitated with $10 \%$ (w/v) trichloroacetic acid (TCA). The cell pellet was resuspended with $0.3 \mathrm{ml} \mathrm{PBS}$ ( $\mathrm{pH} 7.4$ ). The suspension was then mixed with $0.2 \mathrm{ml} p$ xylene for $5 \mathrm{~min}$ at room temperature and centrifuged at $2500 \mathrm{~g}$ for $10 \mathrm{~min}$ at $4{ }^{\circ} \mathrm{C}$. The organic layer was discarded and the aqueous layer was mixed with $1.2 \mathrm{ml}$ acetone and maintained at $-20{ }^{\circ} \mathrm{C}$ to precipitate the secreted surface proteins. The cell pellet was collected and used for preparation of intracellular proteins (ICPs). The extracellular proteins (ECPs) consisted of the fraction of detached surface proteins plus the fraction of supernatant proteins. 
For subcellular fractionation, the cytoplasmic membrane and the cytoplasm proteins were prepared using the method described by Neyt \& Cornelis (1999). Briefly, Ed. tarda bacteria cultured in DMEM were harvested from the supernatant, and the supernatant proteins were separated by precipitation with $10 \%$ TCA as described above. The bacterial cells were resuspended in $10 \mathrm{mM}$ cold Tris/ $\mathrm{HCl}$ ( $\mathrm{pH}$ 8.0) and $5 \mathrm{mM} \mathrm{MgCl}$, and sonicated. The cellular debris was precipitated by centrifugation at $10000 \mathrm{~g}$ for $5 \mathrm{~min}$, and the supernatant was centrifuged for $30 \mathrm{~min}$ at $100000 \mathrm{~g}$ to separate the membrane (insoluble) fraction from the cytosolic (soluble) fraction.

Each protein sample was dissolved in $50 \mu \mathrm{l}$ ReadyPrep reagent 3 (Bio$\mathrm{Rad})$, and an equal volume (10 $\mu$ l per lane) of each fraction was loaded on the SDS-PAGE gel for Western blotting.

2D PAGE and Western blotting. 2D PAGE was performed as previously described (Srinivasa Rao et al., 2004). For Western blotting, protein fractions were resolved by $12 \%$ SDS-PAGE and electrotransferred onto nitrocellulose membranes according to the method described by Towbin et al. (1979). EscA and EseC were detected by incubation overnight at $4{ }^{\circ} \mathrm{C}$ with a $1: 1000$ dilution of anti-EscA and anti-EseC rabbit polyclonal antibodies, respectively, followed by a $1: 2000$ dilution of goat anti-rabbit IgG conjugated to horseradish peroxidase (Sigma). Antibody complexes were detected by development in 3,3-diaminobenzidine tetrahydrochloride (DAB). Anti-DnaK monoclonal antibody (Merck) was used at a dilution of $1: 2000$ for detection of cell fractions.

The relative concentration of EseC in cell fractions was estimated by refractive densitometry using a Fluor-S Multi-imager (Bio-Rad) in the reflective mode. Values were calculated from optical density units $(\mathrm{ODu})$ adjusted for band volume $\left(\mathrm{ODu} \times \mathrm{mm}^{2}\right)$ using the Quantity One 4.3.0 software package (Bio-Rad). Wild-type EseC protein in the ECP fraction was used as an internal quantity standard. Three individual repetitions were analysed for each experiment.

Construction of transcriptional and translational fusions, and $\boldsymbol{\beta}$-galactosidase assay. Plasmids pVIK112 and pVIK111 have been used to study the regulation of genes at the transcriptional and the translational levels (Kalogeraki \& Winans, 1997). For the construction of LacZ transcriptional or translational strains, a $486 \mathrm{bp}$ internal fragment (corresponding to positions $902-1387 \mathrm{bp}$ ) of eseC was amplified from PPD130/91 genomic DNA and introduced into the

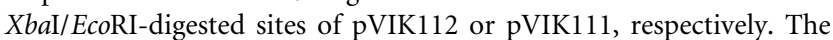
resulting plasmids were transferred from S17-1 $\lambda$ pir into wild-type $E d$. tarda or the $\Delta e s c A$ mutant strain via conjugation and integrated into the chromosome by homologous recombination. The resulting strains (eseC::pVIK111, eseC::pVIK112, $\Delta e s c A$ eseC::pVIK111 and $\triangle e s c A$ eseC::pVIK112) were grown in DMEM for $24 \mathrm{~h}$ at $25{ }^{\circ} \mathrm{C}$ with $5 \%$ $(\mathrm{v} / \mathrm{v}) \mathrm{CO}_{2}$. Bacterial cells were harvested and $\beta$-galactosidase activity was measured as described by Zheng et al. (2007). Each measurement was performed with triplicate samples.

Analysis of EseC stabilization. Ed. tarda wild-type and $\Delta e s c A$ strains were grown in DMEM at $25{ }^{\circ} \mathrm{C}$ with $5 \%(\mathrm{v} / \mathrm{v}) \mathrm{CO}_{2}$ to an $\mathrm{OD}_{540}$ of 0.5 . Chloramphenicol was then added to a final concentration of $200 \mu \mathrm{g}$ $\mathrm{ml}^{-1}$ to inhibit protein synthesis. Bacterial cultures $(1.5 \mathrm{ml})$ were sampled at $15 \mathrm{~min}$ intervals from time 0 to $120 \mathrm{~min}$. Ed. tarda cells were collected by centrifugation $\left(12000 \mathrm{~g}, 4{ }^{\circ} \mathrm{C}, 2 \mathrm{~min}\right)$, and the bacterial samples were boiled in the SDS-PAGE loading buffer (Fermentas) for $5 \mathrm{~min}$ and analysed by Western blotting using anti-EseC sera.

Co-immunoprecipitation of EscA and EseC. An experiment for co-immunoprecipitation of EscA and EseC was performed using the Seize primary immunoprecipitation kit (Pierce). A $200 \mu$ volume of the beads was mixed with $100 \mu \mathrm{g}$ of the purified anti-EscA antibody, and the mixture was incubated with gentle shaking at room temperature for $4 \mathrm{~h}$. After washing, the mixture was incubated with the ECPs or ICPs overnight at $4{ }^{\circ} \mathrm{C}$ with shaking. After washing the mixture three times with washing buffer, the complexes were recovered from the beads with elution buffer. The purified proteins were then analysed by SDS-PAGE followed by Western blotting with anti-EseC and anti-EscA sera.

Co-purification assay. The interactions of EscA-EseC and EscAEseC $\Delta$ were determined by co-purification of the $\mathrm{His}_{6}$-EscA + EseC and $\mathrm{His}_{6}$-EscA $+\mathrm{EseC} \Delta$ complexes in a $\mathrm{Ni}^{2+}$-NTA column. After induction with $1 \mathrm{mM}$ IPTG, bacteria containing the corresponding recombinant plasmids were harvested and resuspended in NTM buffer $[300 \mathrm{mM} \mathrm{NaCl}, 50 \mathrm{mM}$ Tris/HCl $(\mathrm{pH} \mathrm{8.0)}, 10 \mathrm{mM} \quad \beta$ mercaptoethanol] supplemented with $20 \mathrm{mM}$ imidazole before being lysed by sonication. Then the lysates were cleared by centrifugation and incubated at $4{ }^{\circ} \mathrm{C}$ for $1 \mathrm{~h}$ with $50 \mu \mathrm{Ni}^{2+}$-NTA agarose beads, with gentle mixing. The suspensions were successively transferred into a column and washed five times with NTM buffer supplemented with $30 \mathrm{mM}$ imidazole. The bound proteins were eluted from the column with $50 \mu \mathrm{l}$ NTM buffer supplemented with $200 \mathrm{mM}$ imidazole.

Virulence of mutant Ed. tarda in fish. Healthy naïve blue gourami fish (Trichogaster trichopterus Pallas) were infected with Ed. tarda wild-type and mutant strains as previously described (Ling et al., 2000). The mortality of the fish was recorded over a period of 7 days after intramuscular injection. The $\mathrm{LD}_{50}$ values were calculated according to the method developed by Reed \& Muench (1938).

\section{RESULTS}

\section{Influence of EscA on the accumulation and secretion of EseC}

Chaperones for the type III secretion translocon components and effectors often affect the secretion and/or stabilization of the target proteins (Page \& Parsot, 2002). To ascertain the role of $e s c A$, a non-polar in-frame deletion mutant of $\triangle e s c A$ was constructed. The $\triangle e s c A$ mutant and the wild-type strain were grown in DMEM at $25{ }^{\circ} \mathrm{C}$ in a $5 \%(\mathrm{v} / \mathrm{v}) \mathrm{CO}_{2}$ incubator to induce the expression of the T3SS proteins. The supernatant of each strain was collected and analysed by 2D PAGE (Fig. 1C). Significantly, the $\triangle e s c A$ mutant was determined to have lost the EseC protein in the supernatant, yet still displayed the characteristic EseB and EseD protein spots.

ECPs containing the proteins secreted on the cell surface and into the culture medium were collected from the wildtype, $\triangle e s c A$ and $\triangle e s c A+e s c A$ strains. Samples representing the equivalent number of bacteria were loaded and analysed by Western blotting. As illustrated in Fig. 1(D), EscA was not detected in ECPs, and the secretion of EseC was greatly decreased ( $1.5 \pm 0.5$ relative units) (lane 2$)$ in the $\Delta e s c A$ mutant compared to that in the wild-type strain (100 relative units) (lane 1). The phenotype of decreased secretion of EseC was due to the mutation of escA, as complementing the $\Delta e s c A$ mutant with escA restored the secretion of EseC ( $95.2 \pm 3.0$ relative units) (lane 3) to almost the wild-type level. As calculated, the wild-type strain produced about 136.6 relative units of EseC (100.0 in ECP and $36.6 \pm 3.4$ in ICP), but the $\Delta e s c A$ mutant produced about 11.2 relative units of EseC $(1.5 \pm 0.5$ in 


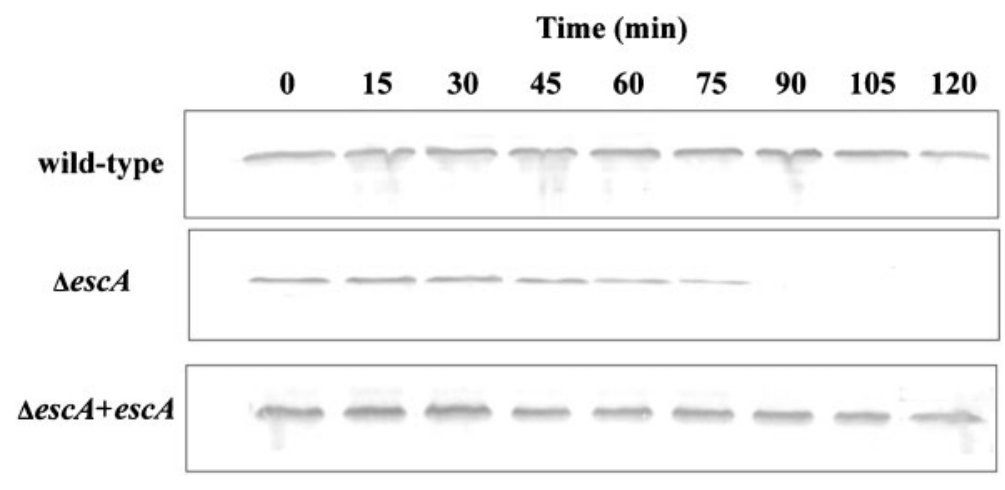

Fig. 2. Effect of EscA on the stabilization of EseC. Ed. tarda wild-type and $\triangle e s c A$ strains were grown in DMEM at $25{ }^{\circ} \mathrm{C}$ with $5 \%(\mathrm{v} / \mathrm{v})$ $\mathrm{CO}_{2}$ to an $\mathrm{OD}_{540}$ of 0.5 . Chloramphenicol $\left(200 \mu \mathrm{g} \mathrm{ml}^{-1}\right)$ was then added to the medium. Bacterial cultures were sampled at $15 \mathrm{~min}$ intervals and equal amounts of cells $\left(O D_{540}\right.$ 0.5) were analysed by Western blotting using anti-EseC polyclonal antibody.

ECP and $9.7 \pm 1.2$ in ICP). Thus, only $13.4 \%$ of EseC was secreted in the absence of escA, while $73.2 \%$ of EseC was secreted in the wild-type strain. The accumulation and secretion of EseB and EseD were not obviously affected in the $\Delta e s c A$ mutant and were comparable to those of the wild-type strain and the complemented strain (Fig. 1D and data not shown). This finding suggested that esc $A$ affects the accumulation and secretion of EseC in Ed. tarda.

\section{Influence of EscA on the stabilization of EseC in Ed. tarda}

To determine whether the reduced amount of accumulation or secretion of EseC was due to the reduced stabilization of this protein in the absence of escA, the amount of EseC in the Ed. tarda culture was monitored after adding chloramphenicol to inhibit bacterial protein synthesis. As shown in Fig. 2, in the presence of chloramphenicol the amount of EseC in the $\Delta e s c A$ mutant gradually reduced over time, and was practically undetectable after $90 \mathrm{~min}$. However, the amounts of EseC in the wild-type and complemented strains were not affected during the monitoring period. This result demonstrated that EscA may affect the stabilization of EseC.

\section{Lack of influence of EscA on the transcription of esec}

Some chaperones reportedly affect the transcription and even the translation of their cognate substrates (Tucker \& Galán, 2000; Darwin \& Miller, 2001). Therefore, the effect of $\Delta e s c A$ on EseC could be partially explained by EscA's alteration of the transcription and/or translation of the ese $C$ gene. To investigate this possibility, we examined the effect of a deletion mutation in escA on EseC at the transcription and translation levels. Following the method described in Methods, a 486 bp fragment of eseC (positions 902-1387 bp) was transferred into plasmids pVIK112 and pVIK111, creating $\beta$-galactosidase transcriptional and translational fusions, respectively. The resultant plasmids were then integrated into the chromosomes of Ed. tarda wild-type strain and $\triangle e s c A$ mutant, creating the transcriptional fusion strains eseC::pVIK112 and $\triangle e s c A$ eseC::pVIK112 and the translational fusion strains eseC::pVIK111 and $\triangle e s c A$ eseC::pVIK111, respectively.
The resultant strains, containing the intact $\mathrm{N}$-terminus of EseC (462 residues), were selected by PCR. Cells of the fused strains were collected and used for measuring $\beta$-galactosidase activities. No significant difference in $\beta$-galactosidase activity was observed between eseC: :pVIK112 (55 12 Miller units) and $\Delta e s c A$ eseC::pVIK112 (58 \pm 5 Miller units) $(P>0.05)$, suggesting that the deletion of escA did not affect the transcription of EseC-LacZ in the bacteria. In contrast, the $\beta$-galactosidase activity in $\Delta e s c A$ eseC::pVIK111 $(6 \pm 4$ Miller units) was reduced approximately 5-10-fold compared to that in eseC::pVIK111 (48 \pm 10 Miller units), demonstrating that esc $A$ affected the EseC-LacZ level in the bacteria $(P<0.05)$. Because the $\triangle e s c A$ eseC: $\mathrm{pVIK} 111$ strain detected contained the intact $\mathrm{N}$-terminus of EseC, it is impossible that the decrease in $\beta$-galactosidase activity was due to the absence of the interaction region of EseC-EscA, which was located at residues 31-137 of EseC (see below). Furthermore, the results supported the conclusion that deletion of escA might affect the stabilization of EseC in the cytoplasm due to the fact that $\triangle e s c A$ did not affect the transcription of eseC. However, the possibility cannot be excluded that EscA could play a role in the translation of EseC.

\section{Localization of EscA to the membrane and the cytoplasm}

Based on the lack of any recognizable signal peptide sequence in EscA, it was hypothesized that EscA would be localized in the bacterial cytosol, like its homologues (Neyt \& Cornelis, 1999). To examine the cellular location of EscA, protein fractions of supernatant, membrane (insoluble) and cytoplasm (soluble) from wild-type, $\Delta \operatorname{esc} A$ and complemented strains were analysed by Western blotting. As illustrated in Fig. 3, EscA was detected in both the soluble and insoluble fractions in the wild-type and complemented strains. However, it was not detected in the supernatant fractions or in the $\Delta e s c A$ background. DnaK, a cytosolic protein, was found only in the soluble fractions and was absent in the ECPs and insoluble fractions, indicating that the membrane fractions were not contaminated by the bacterial cytoplasm. These results suggested that EscA is not a secreted protein but a protein located in the cytoplasm and on the bacterial membrane. 


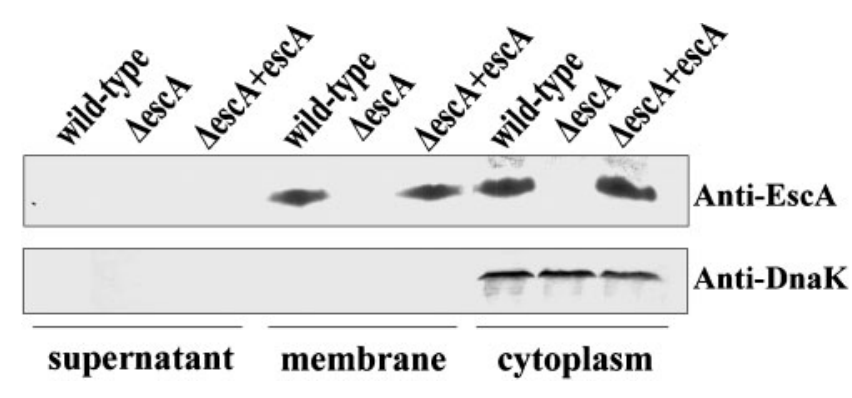

Fig. 3. Localization of EscA within Ed. tarda cells. Wild-type, $\triangle \operatorname{esc} A$ and $\triangle \operatorname{esc} A+\operatorname{esc} A$ bacteria were cultured in DMEM at $25{ }^{\circ} \mathrm{C}$ with $5 \%(\mathrm{v} / \mathrm{v}) \mathrm{CO}_{2}$ for $24 \mathrm{~h}$. The supernatant, insoluble (membrane proteins), and soluble (cytoplasm proteins) fractions were extracted and analysed by Western blotting using the antiEscA polyclonal antibody. Anti-DnaK was used to confirm the effective fractionation.

However, it is possible that EscA formed small insoluble aggregates and was fractionated with the insoluble fractions, and was therefore detected in these fractions.

\section{Association of EscA and EseC in E. coli and Ed. tarda}

Chaperones often perform their function by associating specifically with their cognate substrates (Daniell et al., 2001; Zheng et al., 2007). We hypothesized that the influence of EscA on EseC is mediated via protein-protein interaction. To investigate the potential interaction between EscA and EseC, the pETDuet-1 co-expression system and the $\mathrm{His}_{6}$-tag purification system were exploited in the sense that only proteins linked with $\mathrm{His}_{6}$ were eluted from $\mathrm{Ni}^{2+}$-NTA agarose beads. A plasmid (pAC) that encodes both $\mathrm{His}_{6}$-EscA and EseC was generated, and the proteins were produced simultaneously in E. coli BL21(DE3)/pLysS. To serve as controls, plasmids encoding $\mathrm{His}_{6}$-EscA (pA1), $\mathrm{His}_{6}$-EseC (pC1, with eseC in MCS1), and EseC (pC2, with eseC in MCS2) were constructed. After overproduction of these proteins in E. coli, clear extracts were mixed with $\mathrm{Ni}^{2+}$-NTA agarose beads and proteins adsorbed on the beads were analysed by Western blotting. The result (Fig. 4A) clearly indicated that $\mathrm{EseC}$ was co-purified with $\mathrm{His}_{6}$-EscA (pAC). As negative controls, only EseC or EscA alone was detected on the $\mathrm{Ni}^{2+}$-NTA beads incubated with extracts from bacteria expressing $\mathrm{His}_{6}-\mathrm{EseC}(\mathrm{pC1})$ or $\mathrm{His}_{6}{ }^{-}$ EscA (pA1), respectively. These results demonstrated that EseC and EscA specifically interact with each other in vitro.

Overproduction of EseC (which reacts with anti-EseC antibody) in E. coli produced multiple lower bands, while $\mathrm{His}_{6}$-EseC (pC1) produced more bands than $\mathrm{His}_{6}$-EscA$\mathrm{EseC}(\mathrm{pAC})$, suggesting that the interaction between EscA and EseC may also be important for the stabilization of $\mathrm{EseC}$ in vitro. To investigate this effect in detail, the EseC patterns expressed in E. coli were analysed without co-purification in the absence and in the presence of EscA. As shown in Fig. 4(B), the reaction between $\mathrm{His}_{6}$ $\mathrm{EseC}(\mathrm{pC} 1)$ and anti-EseC resulted in a greater number of low bands than $\mathrm{His}_{6}$-EscA-EseC (pAC), regardless of the ITPG induction time $(1,2,3$ or $4 \mathrm{~h})$. Thus the data showed that the presence of EscA causes the EseC protein to be more stable in E. coli, supporting the finding that EscA is required for the stabilization of EseC.

The fractionation experiments which showed that EscA and $\mathrm{EseC}$ were both found in the cytoplasm of $E d$. tarda suggested that the two proteins may interact with each other in vivo. To demonstrate such an interaction, experiments were conducted to co-immunoprecipitate this putative complex. Synthesis of T3SS proteins was induced in the wild-type, $\Delta e s c A$ and complemented strains. The cell pellets were collected and washed with $p$-xylene to eliminate secreted T3SS proteins that could be absorbed to the outer membrane. After sonication, the clear extracts were incubated with anti-EscA polyclonal antibody and the complex was recovered on Protein A-Sepharose beads. The purified proteins were analysed by Western blotting after washing and eluting. As shown in Fig. 4(C), EscA and EseC were recovered from the extracts of the wild-type and complemented strains, but not from the $\Delta e s c A$ mutant, indicating that cytoplasmic EseC is physically associated with EscA in bacterial cells. These results provided strong evidence that EscA and EseC are associated in Ed. tarda.

\section{Localization of the binding region in EseC}

Having determined that EscA and EseC interact with each other in vitro and in vivo, we attempted to identify the interaction site that contributes to the formation of the EscA-EseC complex. A series of eight in-frame deletion mutations spanning the entire $e s e C$ gene were constructed to determine a discrete binding site in EseC (Table 1). These deletions removed all of the characteristic regions of the protein, including two hypothetical transmembrane helices spanning residues 194-243 and 255-318, and two coiled-coils spanning residues 138-193 and 430-506. All of the truncated proteins were individually co-expressed with EscA in E. coli BL21(DE3)/pLysS. The bacterial lysate, not mixed with the $\mathrm{Ni}^{2+}$-NTA agarose beads, was used as the input fraction to confirm protein production in the coexpression system by Western blotting. As illustrated in Fig. 5(A), all of the proteins with the expected size were produced in the co-expression system. Subsequently, the clear extracts were mixed with $\mathrm{Ni}^{2+}$-NTA agarose beads, and proteins adsorbed on the beads were analysed by Western blotting. As shown in Fig. 5(B), truncated proteins expressed from mutations of ese $C_{\Delta 1-30}$, ese $C_{\Delta 138-193}$, ese $C_{\Delta 194-243}$, ese $C_{\Delta 255-318}, e s e C_{\Delta 319-402}, e s e C_{\Delta 403-429}$ and ese $C_{\Delta 430-506}$ were co-purified with EscA. However, protein expressed from the mutation of $e e_{\Delta 31-137}$ failed to be co-purified with EscA, implying that residues 31-137 of EseC $\left(\mathrm{EseC}_{31-137}\right)$ are likely to be involved in the binding site for EscA. 

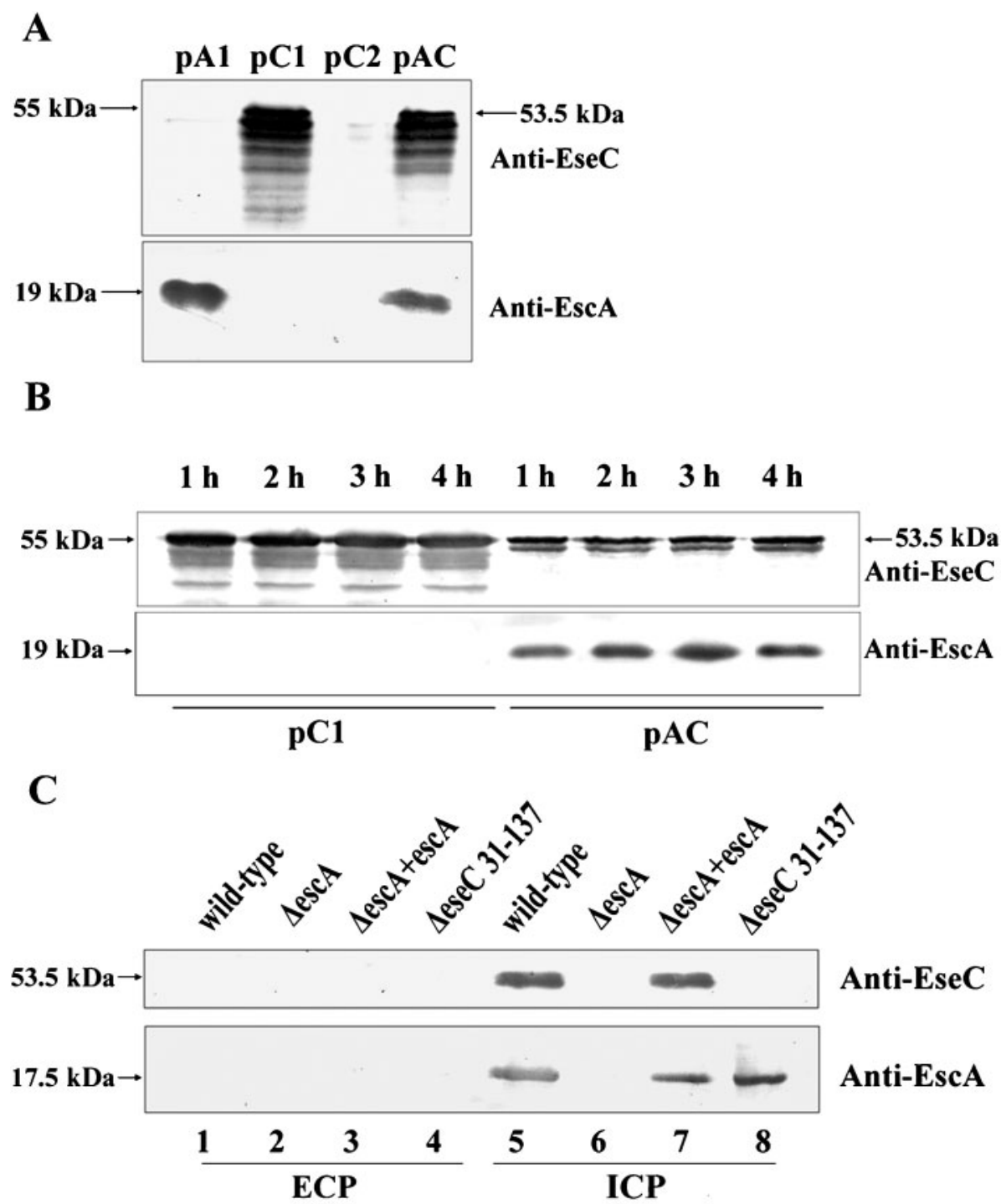

Fig. 4. Interaction between EscA and EseC. (A) Co-purification of EseC with EscA in E. coli. E. coli BL21(DE3)/pLysS

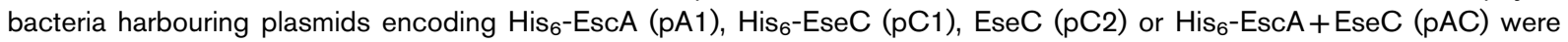
cultured in LB medium at $37{ }^{\circ} \mathrm{C}$. Cultures induced with $1 \mathrm{mM} \mathrm{IPTG}$ were collected at $4 \mathrm{~h}$ and adjusted to $\mathrm{OD}_{540} 0.5$. The clear extracts of equal amounts of bacterial cells were incubated with $\mathrm{Ni}^{2+}$-NTA agarose beads and the proteins binding to the beads were analysed by Western blotting using anti-EscA and anti-EseC polyclonal antibodies. (B) Expression patterns of EseC in the presence and absence of EscA in E. coli. Cultures of E. coli BL21(DE3)/pLysS harbouring plasmids encoding $\mathrm{His}_{6}$-EseC $(\mathrm{pC} 1)$ or $\mathrm{His}_{6}-\mathrm{EscA}+\mathrm{EseC}(\mathrm{pAC})$ were collected 1, 2, 3 and $4 \mathrm{~h}$ after the addition of $1 \mathrm{mM}$ IPTG. The clear extracts of equal amounts of bacterial cells $\left(\mathrm{OD}_{540} 0.5\right)$ were analysed by Western blotting using anti-EseC polyclonal antibody. The lower bands detected with anti-EseC are degradation products of the hybrid proteins. (C) Co-immunoprecipitation of EseC with antiEscA antibody. Ed. tarda wild-type, $\triangle e s c A, \Delta e s c A+e s c A$ and $\Delta e s e C_{31-137}$ strains were cultured in DMEM at $25{ }^{\circ} \mathrm{C}$ with $5 \%$ (v/v) $\mathrm{CO}_{2}$ for $24 \mathrm{~h}$. Co-immunoprecipitates were prepared from ECPs (lanes 1-4) and the soluble ICPs (lanes 5-8) of each strain as described in Methods, and analysed by Western blotting using anti-EscA and anti-EseC polyclonal antibodies.

\section{Interaction of $\mathrm{EseC}_{\mathbf{3 1 - 1 3 7}}$ with EscA in Ed. tarda}

Because $\mathrm{EseC}_{31-137}$ was demonstrated to be the binding region with EscA in vitro, experiments were conducted to determine whether this region interacts with EscA in vivo. Ed. tarda mutant $\Delta$ ese $_{31-137}$, with codons $31-137$ of eseC deleted, was constructed. Co-immunoprecipitation and Western blotting were performed with the cell pellets of the wild-type strain and $\Delta e s e C_{31-137}$. The results showed that the protein complex of EscA and the truncated EseC was not detected in the ICP of $\Delta e s e C_{31-137}$ (Fig. 4C, lane 8), while the protein complex of EscA and EseC was detected in the wildtype and escA complemented strains (Fig. 4C, lanes 5 and 7). As a negative control, this protein complex was not detected in the ECPs of these bacteria. The failure of $\mathrm{EseC}_{\Delta 31-137}$ to 

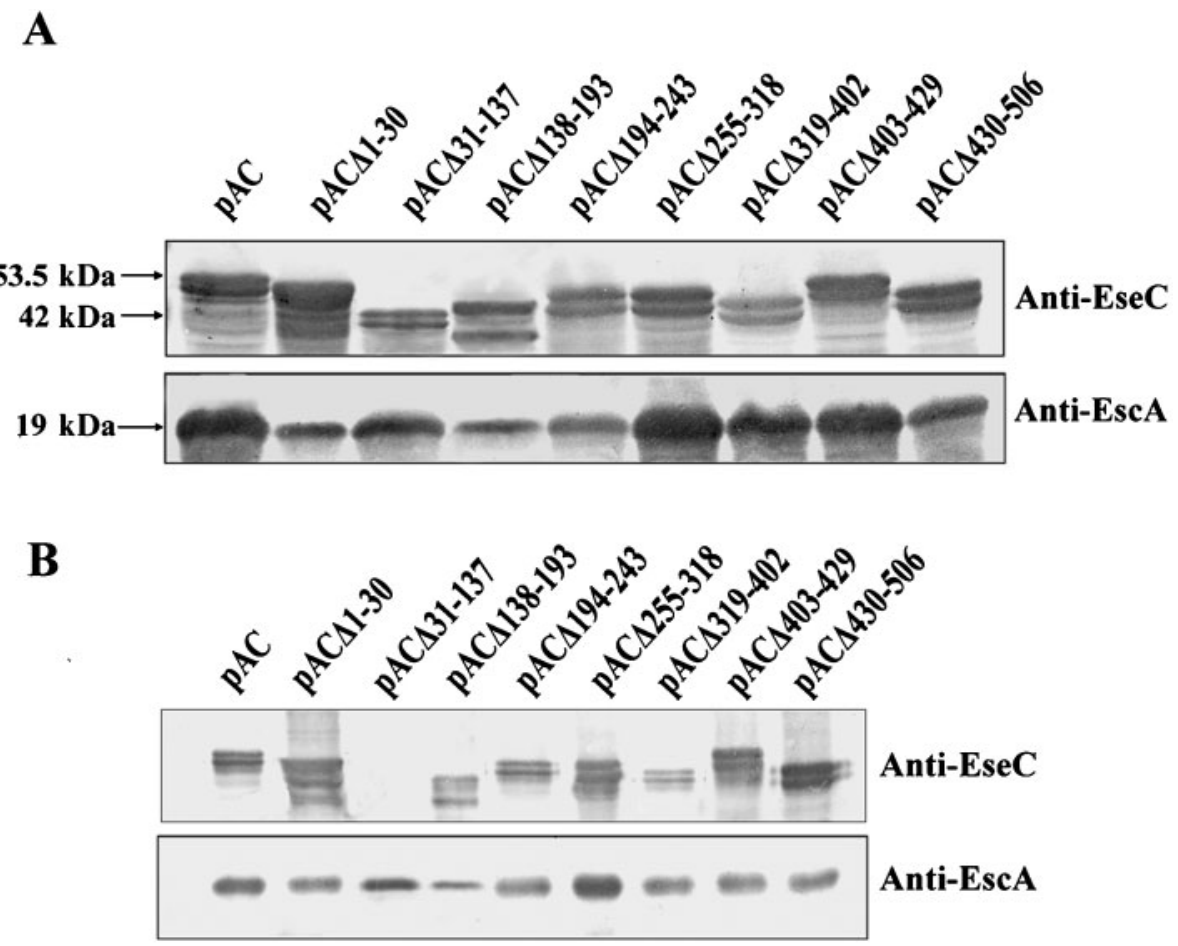

Fig. 5. Localization of the binding segment in EseC. (A) Expression analysis of $\mathrm{His}_{6}-\mathrm{EscA}_{\mathrm{A}}+\mathrm{EseC}_{\Delta}$. E. coli BL21(DE3)/pLysS strains harbouring plasmids encoding $\mathrm{His}_{6}-\mathrm{Esc}_{\mathrm{A}} \mathrm{EseC}(\mathrm{pAC}), \mathrm{His}_{6}-\mathrm{Esc}_{\mathrm{A}}+\mathrm{EseC}_{\Delta 1-30}\left(\mathrm{pAC} \mathrm{C}_{\Delta 1-30}\right), \mathrm{His}_{6}-\mathrm{Esc}_{\mathrm{s}} \mathrm{A}+\mathrm{EseC}_{\Delta 31-137}$ $\left(\mathrm{pAC}_{\Delta 31-137}\right), \mathrm{His}_{6}-\mathrm{Esc}_{\mathrm{A}}+\mathrm{EseC}_{\Delta 138-193}\left(\mathrm{pAC}_{\Delta 138-193}\right), \mathrm{His}_{6}-\mathrm{Esc}_{\mathrm{A}}+\mathrm{EseC}_{\Delta 194-243}\left(\mathrm{pAC} \mathrm{C}_{\Delta 194-243}\right), \mathrm{His}_{6}-\mathrm{Esc}_{\mathrm{A}} \mathrm{A}+\mathrm{EseC}_{\Delta 255-318}$

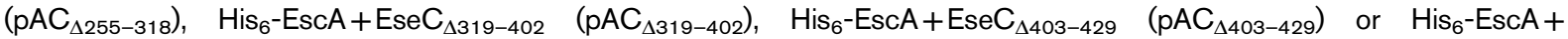
EseC $_{\Delta 430-506}\left(\mathrm{pAC}_{\Delta 430-506}\right)$ were cultured in LB medium at $37^{\circ} \mathrm{C}$. Bacterial cultures induced by $1 \mathrm{mM}$ IPTG were collected at $4 \mathrm{~h}$. The clear extracts of equivalent amounts of bacterial cells $\left(O D_{540} 0.5\right)$ were analysed by Western blotting using anti-EscA and anti-EseC polyclonal antibodies. (B) Localization of the EseC binding segment with EscA. Upon confirmation of the production of recombinant EscA and $\mathrm{EseC}_{\Delta}$ proteins in the co-expressed system in $(A)$, the clear extracts in $(A)$ were incubated with $N i^{2+}-N T A$ agarose beads and the proteins binding to the beads were analysed by Western blotting using anti-EscA and anti-EseC polyclonal antibodies.

bind to EscA suggested that residues 31-137 in EseC are required for the interaction with EscA in $E d$. tarda.

To investigate the effect of $\mathrm{EseC}_{\Delta 31-137}$ on the secretion of EseC in Ed. tarda, ECP and ICP from the induced culture of $\Delta e s e C_{31-137}$ were collected and analysed by Western blotting. As shown in Fig. 6, accumulation of the smaller EseC $_{\Delta 31-137}$ protein was observed in the ICP $(12.3 \pm 1.2$ relative units), but not in the ECP ( 0.0 relative units) of the $\Delta e s e C_{31-137}$ mutant. The amount of $\mathrm{EseC}_{\Delta 31-137}$ in the ICP was comparable to the amount of $\mathrm{EseC}(12.1 \pm 1.0$ relative units) in the ICP of the $\triangle e s c A$ mutant, both of which accounted for about $31 \%$ of the $\mathrm{EseC}(38.7 \pm 2.6$ relative units) in the ICP of the wild-type strain. This finding indicated that $\mathrm{EseC}_{31-137}$ is required for the accumulation and secretion of EseC by interacting with EscA in Ed. tarda.

\section{Contribution of EscA and EseC ${ }_{\Delta 31-137}$ to the virulence of Ed. tarda}

EseC has been reported to contribute to the pathogenesis of Ed. tarda (Tan et al., 2005). To further investigate if this contribution is related to the normal secretion of $\mathrm{EseC}$, the $\mathrm{LD}_{50}$ values of the $\Delta e s c A$ and $\Delta e s e C_{31-137}$ mutants in blue gourami fish were examined. The deletion of escA increased the $\mathrm{LD}_{50}$ value by about $1 \log \left(10^{6.1}\right)$ compared to the wildtype strain $\left(10^{5.1}\right)$, while the complemented strain restored the $\mathrm{LD}_{50}$ value $\left(10^{5.3}\right)$ to approximately the same level as that of the wild-type strain. Similarly, $\Delta e s e C_{31-137}$ also resulted in approximately $1 \log$ increase in the $\mathrm{LD}_{50}$ value $\left(10^{5.9}\right)$. These results indicated that EscA and residues 31137 of EseC contribute to the pathogenesis of Ed. tarda.

\section{DISCUSSION}

Previous studies have shown that $E d$. tarda utilizes a T3SS for its pathogenesis (Tan et al., 2005). EseB, EseC and EseD are T3SS-dependent secreted proteins and form a translocon complex after their secretion (Zheng et al., 2007). EscC is a specific chaperone for $\mathrm{EseB}$ and $\mathrm{EseD}$ (Zheng et al., 2007), while no chaperone for EseC has hitherto been identified. In this study, escA was demonstrated to function as a specific chaperone for EseC. EscA possesses the 


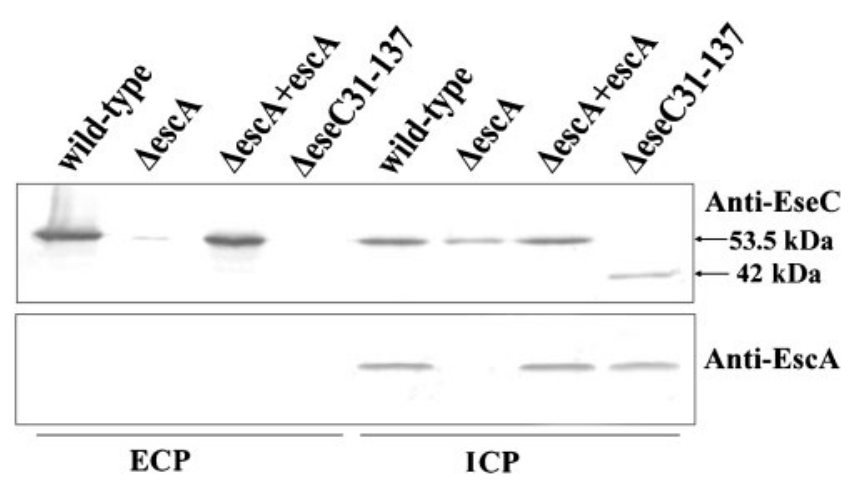

Fig. 6. Effect of the $\mathrm{EseC}_{31-137}$ segment on the accumulation and secretion of EseC. Ed. tarda wild-type, $\Delta$ escA mutant, $\Delta$ esc $A+$ esc $A$ and $\Delta e s e C_{31-137}$ strains were cultured in DMEM at $25^{\circ} \mathrm{C}$ with $5 \%(\mathrm{v} / \mathrm{v}) \mathrm{CO}_{2}$ for $24 \mathrm{~h}$. The ECPs and ICPs of each strain were extracted from equivalent amounts of cells $\left(O D_{540} 0.5\right)$ and analysed by Western blotting using anti-EscA and anti-EseC polyclonal antibodies. Relative units of EseC protein, as measured with the Fluor-S Multi-imager (Bio-Rad), were as follows: wild-type ECP, $100.0 ; \Delta e s c A$ mutant ECP, $1.8 \pm 0.4 ; \Delta e s c A+e s c A$ ECP, $100.3 \pm 2.1 ; \Delta$ ese $_{31-137}$ ECP, 0; wild-type ICP, 38.7 \pm 2.6 ; $\Delta e s c A$ mutant ICP, $12.1 \pm 1.0 ; \Delta e s c A+e s c A$ ICP, $36.9 \pm 1.9$; and $\operatorname{seseC}_{31-137} \mathrm{ICP}, 12.3 \pm 1.2$.

common characteristics of a T3SS chaperone, including a low molecular mass (17.5 kDa), an acidic pI (4.79) and a proximate location of the encoding gene to that of its cognate substrate EseC. The data showed that EscA affects the accumulation and stability of cytoplasmic EseC, as well as its secretion into the culture medium, and the effect of EscA on EseC was demonstrated to be post-transcriptional. As an ICP, EscA interacts with EseC in vitro and in vivo, and a defined region of residues 31-137 in $\mathrm{EseC}\left(\mathrm{EseC}_{31-137}\right)$ is necessary for this interaction. Moreover, $\mathrm{EseC}_{31-137}$ affects the accumulation and secretion of $\mathrm{EseC}$ in $\mathrm{Ed}$. tarda. Finally, challenge experiments with blue gourami fish demonstrated that both EscA and $\mathrm{EseC}_{31-137}$ contribute to the virulence of $E d$. tarda.

Mutation in EscA reduces the accumulation and secretion of EseC, but has a less severe effect than mutations in some EscA homologues such as SycD/LcrH in Yersinia, CesD and CesD2 in EPEC and SseA in Salmonella, which almost abolish the accumulation and secretion of their cognate substrates (Neyt \& Cornelis, 1999; Waterman \& Holden, 2003; Zurawski \& Stein, 2003; Edqvist et al., 2006). EspD in EPEC requires two chaperones (CesD and CesD2) for complete secretion and accumulation activities (Neves et al., 2003; Waterman \& Holden, 2003). The similarity of EseC to EspD leads to the hypothesis that more than one chaperone may exist for EseC. Moreover, even in the presence of EscA, degradation of EseC can be found in the input fractions of $\mathrm{His}_{6}$-EscA + EseC (pAC) (Fig. 4B), implying that EscA does not completely protect $\mathrm{EseC}$ from degradation. A putative additional chaperone may exist in native $E d$. tarda that is necessary for the stability of EseC. Because EseC is not secreted in the absence of eseE (Zheng et al., 2007), EseE may act as a second chaperone. Further study is needed to clarify this hypothesis.

Unlike most T3SS chaperones localized in the cytoplasm, EscA was found both on the cytoplasmic membrane and in the cytoplasm. A limited number of NF-T3SS chaperones are reported to be membrane-associated, such as CesD and CesT from EPEC (Elliott et al., 1999; Wainwright \& Kaper, 1998), YscB from Yersinia (Jackson et al., 1998), SseA from Salmonella (Zurawski \& Stein, 2003) and EscC from Ed. tarda (Zheng et al., 2007). This finding is reminiscent of the function of the F-T3SS chaperone. During F-T3SS protein export, the chaperone-substrate complexes dock at the membrane ATPase (Gauthier \& Finlay, 2003; Thomas et al., 2004), which facilitates the release of the chaperone from the cognate secreted substrate in an ATP-dependent manner (Akeda \& Galán, 2005). After release by an escort mechanism in F-T3SS protein export, free chaperones can be cycled (Evans et al., 2006). Thus, chaperone transition between cytosol and membrane compartments facilitates F-T3SS export of the flagellar component and, by extension, facilitates secretion of NF-T3SS proteins. This view is supported by previous research relating to EPEC T3SS, which indicated that the chaperone CesT and its export substrate Tir can interact independently or collectively with ATPase EscN (Gauthier \& Finlay, 2003); CesT recruits Tir and they co-localize to the EPEC inner membrane (Thomas et al., 2005). Therefore, membrane association may be a necessary step for the interaction of the secreted protein-chaperone complex with T3SS ATPase. These findings may help to explain the dual location of EscA.

The fact that EseC requires residues 31-137 for binding EscA and for its accumulation and secretion is consistent with studies showing that most translocon components associate with their cognate chaperones via the $\mathrm{N}$-terminal regions (Harrington et al., 2003). Transmembrane and coiled-coil domains are found at high frequency among T3SS structural and secreted components and have been shown to play important roles in the function of translocons and effectors (Daniell et al., 2001; Delahay \& Frankel, 2002). In this research, however, the two transmembrane helices ( $\mathrm{EseC}_{194-243}$ and $\left.\mathrm{EseC}_{255-318}\right)$ and the two coiled-coil regions $\left(\mathrm{EseC}_{138-193}\right.$ and $\left.\mathrm{EseC}_{430-506}\right)$ in $\mathrm{EseC}$ were found not to be involved in the interaction. This finding is not exclusive to EseC. Residues 56-99 of YopB, which contain no typical secondary structure, are responsible for binding the cognate chaperone SycD (Neyt \& Cornelis, 1999). The mechanism of this interaction is not clear. However, by using domain linker prediction (Miyazaki et al., 2002), two domain linkers were predicted in EseC, spanning residues 59-84 and 117-122 (data not shown), implying that regions between these two domain linkers possibly possess a functional secondary structure. Supporting this idea, DNASIS analysis confirmed that many short hydrophobic segments were found dispersedly at residues 44-49, 70-76, 80-83, 86-87, 91-92 and 100-101, which may be important with regard to protein-protein interactions (Jones \& Thornton, 1995). Whether these 
hydrophobic segments located within the $\mathrm{N}$-terminus of EseC have effects on the EseC-EscA interaction is yet to be investigated. We also tried to seek a specific binding region in EscA using the same procedure, but such a linear region responsible for binding to EseC was not detected (data not shown). Further study of the structural mechanism of the EscA-EseC interaction is still needed.

The observation that mutation of escA or eseC increases the $\mathrm{LD}_{50}$ value by approximately $1 \log$ unit provides evidence that an intact translocon is essential for the function of the T3SS in the pathogenesis of Ed. tarda. An understanding of this system will provide greater insight into the virulence mechanism of this pathogen. Our results will also aid in the development of new approaches to combating edwardsiellosis. In a previous study, we reported that an attenuated strain mutated in a T3SS gene elicited good protection against edwardsiellosis in fish (Mo et al., 2007). The findings in this study will be very useful in the future for the development of effective attenuated live vaccines against edwardsiellosis. Furthermore, it is unclear at this point whether there is an additional chaperone for $\mathrm{EseC}$, and EscA's regulatory role in the function of T3SS is likewise not understood. The mutants constructed in this research will also be very helpful in future studies attempting to identify the additional chaperone(s) of EseC and the possible regulatory role of EscA in T3SS function.

\section{ACKNOWLEDGEMENTS}

We are grateful to the project of Natural Sciences Foundation of China (30671613), 973 Program (2006CB10803) and 863 Program (2006AA100310) for providing the research grants for this research. We also thank Dr Hai Qi He from Southern Plain Agricultural Research Center, USDA-ARS, USA, for critical reading which helped to improve the manuscript.

\section{REFERENCES}

Akeda, Y. \& Galán, J. E. (2005). Chaperone release and unfolding of substrates in type III secretion. Nature 437, 911-915.

Beuzón, C. R., Banks, G., Deiwick, J., Hensel, M. \& Holden, D. W. (1999). pH-dependent secretion of SseB, a product of the SPI-2 type III secretion system of Salmonella typhimurium. Mol Microbiol 33, 806-816.

Bröms, J. E., Forslund, A. L., Forsberg, A. \& Francis, M. S. (2003). $\mathrm{PcrH}$ of Pseudomonas aeruginosa is essential for secretion and assembly of the type III translocon. J Infect Dis 188, 1909-1921.

Bröms, J. E., Edqvist, P. J., Forsberg, A. \& Francis, M. S. (2006). Tetratricopeptide repeats are essential for PcrH chaperone function in Pseudomonas aeruginosa type III secretion. FEMS Microbiol Lett 256, 57-66.

Büttner, D. \& Bonas, U. (2002). Port of entry - the type III secretion translocon. Trends Microbiol 10, 186-192.

Büttner, C. R., Sorg, I., Cornelis, G. R., Heinz, D. W. \& Niemann, H. H. (2008). Structure of the Yersinia enterocolitica type III secretion translocator chaperone SycD. J Mol Biol 375, 997-1012.

Chen, J. D., Lai, S. Y. \& Huang, S. L. (1996). Molecular cloning, characterization, and sequencing of the hemolysin gene from Edwardsiella tarda. Arch Microbiol 165, 9-17.
Cook, R. A. \& Tappe, J. P. (1985). Chronic enteritis associated with Edwardsiella tarda infection in Rockhopper penguins. J Am Vet Med Assoc 187, 1219-1220.

Cornelis, G. R. \& Van Gijsegem, F. (2000). Assembly and function of type III secretory systems. Annu Rev Microbiol 54, 735-774.

Daniell, S. J., Delahay, R. M., Shaw, R. K., Hartland, E. L., Pallen, M. J., Booy, F., Ebel, F., Knutton, S. \& Frankel, G. (2001). Coiled-coil domain of enteropathogenic Escherichia coli type III secreted protein EspD is involved in EspA filament-mediated cell attachment and hemolysis. Infect Immun 69, 4055-4064.

Daniell, S. J., Kocsis, E., Morris, E., Knutton, S., Booy, F. P. \& Frankel, G. (2003). 3D structure of EspA filaments from enteropathogenic Escherichia coli. Mol Microbiol 49, 301-308.

Darwin, K. H. \& Miller, V. L. (2001). Type III secretion chaperonedependent regulation: activation of virulence genes by SicA and InvF in Salmonella typhimurium. EMBO J 20, 1850-1862.

Delahay, R. M. \& Frankel, G. (2002). Coiled-coil proteins associated with type III secretion systems: a versatile domain revisited. Mol Microbiol 45, 905-916.

Edqvist, P. J., Bröms, J. E., Betts, H. J., Forsberg, A., Pallen, M. J. \& Francis, M. S. (2006). Tetratricopeptide repeats in the type-IIIsecretion chaperone, LcrH: their role in substrate binding and secretion. Mol Microbiol 59, 31-44.

Edwards, R. A., Keller, L. H. \& Schifferli, D. M. (1998). Improved allelic exchange vectors and their use to analyze 987P fimbria gene expression. Gene 207, 149-157.

Elliott, S. J., Hutcheson, S. W., Dubois, M. S., Mellies, J. L., Wainwright, L. A., Batchelor, M., Frankel, G., Knutton, S. \& Kaper, J. B. (1999). Identification of CesT, a chaperone for the type III secretion of Tir in enteropathogenic Escherichia coli. Mol Microbiol 33, 1176-1189.

Evans, L. D., Stafford, G. P., Ahmed, S., Fraser, G. M. \& Hughes, C. (2006). An escort mechanism for cycling of export chaperones during flagellum assembly. Proc Natl Acad Sci U S A 103, 17474-17479.

Francis, M. S., Wolf-Watz, H. \& Forsberg, A. (2002). Regulation of type III secretion systems. Curr Opin Microbiol 5, 166-172.

Gauthier, A. \& Finlay, B. B. (2003). Translocated intimin receptor and its chaperone interact with ATPase of the type III secretion apparatus of enteropathogenic Escherichia coli. J Bacteriol 185, 6747-6755.

Ghosh, P. (2004). Process of protein transport by the type III secretion system. Microbiol Mol Biol Rev 68, 771-795.

Goldstein, E. J., Agyare, E. O., Vagvolgi, A. E. \& Halpern, M. (1981). Aerobic bacterial oral flora of garter snakes: development of normal flora and pathogenic potential for snakes and humans. J Clin Microbiol 13, 954-956.

Hanahan, D. (1983). Studies on transformation of Escherichia coli with plasmids. J Mol Biol 166, 557-580.

Harrington, A. T., Hearn, P. D., Picking, W. L., Barker, J. R., Wessel, A. \& Picking, W. D. (2003). Structural characterization of the $\mathrm{N}$ terminus of IpaC from Shigella flexneri. Infect Immun 71, 1255-1264.

Ide, T., Laarmann, S., Greune, L., Schillers, H., Oberleithner, H. \& Schmidt, M. A. (2001). Characterization of translocation pores inserted into plasma membranes by type III-secreted Esp proteins of enteropathogenic Escherichia coli. Cell Microbiol 3, 669-679.

Jackson, M. W., Day, J. B. \& Plano, G. V. (1998). YscB of Yersinia pestis functions as a specific chaperone for YopN. J Bacteriol 180, 4912-4921.

Janda, J. M. \& Abbott, S. L. (1993). Infections associated with the genus Edwardsiella: the role of Edwardsiella tarda in human disease. Clin Infect Dis 17, 742-748.

Jones, S. \& Thornton, J. M. (1995). Protein-protein interactions: a review of primer dimer structures. Prog Biophys Mol Biol 63, 31-65. 
Kalogeraki, V. S. \& Winans, S. C. (1997). Suicide plasmids containing promoterless reporter genes can simultaneously disrupt and create fusions to target genes of diverse bacteria. Gene 188, 69-75.

Kourany, M., Vasquez, M. A. \& Saenz, R. (1977). Edwardsiellosis in man and animals in Panama: clinical and epidemiological characteristics. Am J Trop Med Hyg 26, 1183-1190.

Ling, S. H., Wang, X. H., Xie, L., Lim, T. M. \& Leung, K. Y. (2000). Use of green fluorescent protein (GFP) to study the invasion pathways of Edwardsiella tarda in in vivo and in vitro fish models. Microbiology 146, 7-19.

Macnab, R. M. (2003). How bacteria assemble flagella. Annu Rev Microbiol 57, 77-100.

Ménard, R., Sansonetti, P. J., Parsot, C. \& Vasselon, T. (1994). Extracellular association and cytoplasmic partitioning of the IpaB and IpaC invasins of S. flexneri. Cell 79, 515-525.

Miller, V. L. \& Mekalanos, J. J. (1988). A novel suicide vector and its use in construction of insertion mutations: osmoregulation of outer membrane proteins and virulence determinants in Vibrio cholerae requires toxR. J Bacteriol 170, 2575-2583.

Miyazaki, S., Kuroda, Y. \& Yokoyama, S. (2002). Characterization and prediction of linker sequences of multi-domain proteins by a neural network. J Struct Funct Genomics 2, 37-51.

Mo, Z. L., Xiao, P., Mao, Y. X., Zou, Y. X., Wang, B., Li, J., Xu, Y. L. \& Zhang, P. J. (2007). Construction and characterization of a live, attenuated esrB mutant of Edwardsiella tarda and its potential as a vaccine against the haemorrhagic septicaemia in turbot, Scophthamus maximus (L.). Fish Shellfish Immunol 23, 521-530.

Neves, B. C., Mundy, R., Petrovska, L., Dougan, G., Knutton, S. \& Frankel, G. (2003). CesD2 of enteropathogenic Escherichia coli is a second chaperone for the type III secretion translocator protein EspD. Infect Immun 71, 2130-2141.

Neyt, C. \& Cornelis, G. R. (1999). Role of SycD, the chaperone of the Yersinia Yop translocators YopB and YopD. Mol Microbiol 31, 143-156.

Nikolaus, T., Deiwichm, J., Rappl, C., Freeman, J. A., Schröder, W., Miller, S. I. \& Hensel, M. (2001). SseBCD proteins are secreted by the type III secretion system of Salmonella pathogenicity island 2 and function as a translocon. J Bacteriol 183, 6036-6045.

Olsson, J., Edqvist, P. J., Bröms, J. E., Forsberg, A., Wolf-Watz, H. \& Francis, M. S. (2004). The YopD translocator of Yersinia pseudotuberculosis is a multifunctional protein comprised of discrete domains. J Bacteriol 186, 4110-4123.

Page, A. L. \& Parsot, C. (2002). Chaperones of the type III secretion pathway: jacks of all trades. Mol Microbiol 46, 1-11.

Pallen, M. J., Beatson, S. A. \& Bailey, C. M. (2005). Bioinformatics, genomics and evolution of non-flagellar type-III secretion systems: a Darwinian perspective. FEMS Microbiol Rev 29, 201-229.

Parsot, C., Hamiaux, C. \& Page, A. L. (2003). The various and varying roles of specific chaperones in type III secretion systems. Curr Opin Microbiol 6, 7-14.

Reed, L. J. \& Muench, H. (1938). A simple method of estimating fifty percent end points. Am J Hyg 27, 493-497.

Rubirés, X., Saigi, F., Piqué, N., Climent, N., Merino, S., Albertí, S., Tomás, J. M. \& Regué, M. (1997). A gene (wbbL) from Serratia marcescens $\mathrm{N} 28 \mathrm{~b}$ (O4) complements the rfb-50 mutation of Escherichia coli K-12 derivatives. J Bacteriol 179, 7581-7586.
Sae-Oui, D., Muroga, K. \& Nakai, T. (1984). A case of Edwardsiella tarda infection in cultured colored carp Cyprinus carpio. Fish Pathol 19, 197-199.

Saier, M. H., Jr (2004). Evolution of bacterial type III protein secretion systems. Trends Microbiol 12, 113-115.

Simon, R., Priefer, U. \& Pühler, A. (1983). A broad host range mobilization system for in vivo genetic engineering: transposon mutagenesis in Gram-negative bacteria. Biotechnology 1, 784-791.

Srinivasa Rao, P. S., Lim, T. M. \& Leung, K. Y. (2001). Opsonized virulent Edwardsiella tarda strains are able to adhere to and survive and replicate within fish phagocytes but fail to stimulate reactive oxygen intermediates. Infect Immun 69, 5689-5697.

Srinivasa Rao, P. S., Yamada, Y. \& Leung, K. Y. (2003). A major catalase (KatB) that is required for resistance to $\mathrm{H}_{2} \mathrm{O}_{2}$ and phagocytemediated killing in Edwardsiella tarda. Microbiology 149, 2635-2644.

Srinivasa Rao, P. S., Yamada, Y., Tan, Y. P. \& Leung, K. Y. (2004). Use of proteomics to identify novel virulence determinants that are required for Edwardsiella tarda pathogenesis. Mol Microbiol 53, 573-586.

Tan, Y. P., Zheng, J., Tung, S. L., Rosenshine, I. \& Leung, K. Y. (2005). Role of type III secretion in Edwardsiella tarda virulence. Microbiology 151, 2301-2313.

Thomas, J., Stafford, G. P. \& Hughes, C. (2004). Docking of cytosolic chaperone-substrate complexes at the membrane ATPase during flagellar type III protein export. Proc Natl Acad Sci U S A 101, 3945-3950.

Thomas, N. A., Deng, W., Puente, J. L., Frey, E. A., Yip, C. K., Strynadka, N. C. \& Finlay, B. B. (2005). CesT is a multi-effector chaperone and recruitment factor required for the efficient type III secretion of both LEE- and non-LEE-encoded effectors of enteropathogenic Escherichia coli. Mol Microbiol 57, 1762-1779.

Thune, R. L., Stanley, L. A. \& Cooper, R. K. (1993). Pathogenesis of gram-negative bacterial infections in warm water fish. Annu Rev Fish Dis 3, 37-68.

Towbin, H., Staehelin, T. \& Gordon, J. (1979). Electrophoretic transfer of proteins from polyacrylamide gels to nitrocellulose sheets: procedure and some applications. Proc Natl Acad Sci U S A 76, 4350-4354.

Tucker, S. C. \& Galán, J. E. (2000). Complex function for SicA, a Salmonella enterica serovar Typhimurium type III secretion-associated chaperone. J Bacteriol 182, 2262-2268.

Wainwright, L. A. \& Kaper, J. B. (1998). EspB and EspD require a specific chaperone for proper secretion from enteropathogenic E. coli. Mol Microbiol 27, 1247-1260.

Waterman, S. R. \& Holden, D. W. (2003). Functions and effectors of the Salmonella pathogenicity island 2 type III secretion system. Cell Microbiol 5, 501-511.

Yang, C. H. \& Wang, C. K. (1999). Edwardsiella tarda bacteraemia complicated by acute pancreatitis and pyomyoma. J Infect 38, 124-126.

Zheng, J. \& Leung, K. Y. (2007). Dissection of a type VI secretion system in Edwardsiella tarda. Mol Microbiol 66, 1192-1206.

Zheng, J., Li, N., Tan, Y. P., Sivaraman, J., Mok, Y. K., Mo, Z. L. \& Leung, K. Y. (2007). EscC is a chaperone for the Edwardsiella tarda T3SS putative translocon components EseB and EseD. Microbiology 153, 1953-1962.

Zurawski, D. V. \& Stein, M. A. (2003). SseA acts as the chaperone for the SseB component of the Salmonella pathogenicity island 2 translocon. Mol Microbiol 47, 1341-1351.

Edited by: P. van der Ley 